\title{
PATTERNS OF TERRESTRIAL PLANT CARBON: LATE MESOZOIC AND CENOZOIC
}

OLSON*, Jerry, Global Patterns Company, Eblen Cave Road, Box 361A, Route 2, Lenoir City, TN 37771, U.S.A.; UPCHURCH, Garland R., Jr., Department of Biology, Southwest Texas State University, San Marcos, TX 78666, U.S.A.

Variation in terrestrial productivity and biomass impacts evolution through linkages between productivity and biodiversity and through the types of resources available for consumption by herbivores. Geographic variation in terrestrial plant carbon is known on a global scale for extant biomes and is strongly correlated with precipitation, temperature, and the area of wetlands. Although estimates of extant terrestrial plant carbon density are still somewhat uncertain, the highest densities clearly occur in tropical and temperate rainforests, and the lowest occur in deserts, semideserts, and arctic/alpine tundra. Patterns of variation in ancient terrestrial plant carbon can be estimated through the correlation between biome/climate and carbon density, provided individual biomes show little change through time in primary productivity or density of plant carbon.

Density of terrestrial plant carbon has been estimated on a global scale for the latest Cretaceous, late Paleocene/Eocene, middle-late Eocene, early Miocene, and Holocene/Recent using the biomal reconstructions of Wolfe (1984), Upchurch (this symposium), and others. Latest Cretaceous (Maastrichtian) estimates indicate a relatively low value of 700-800 gigatons, which may underestimate carbon due to the presence of extensive latest Cretaceous coastal wetlands. However, much of this figure is readliy explainable by extensive deserts in Asia and little evidence for areally extensive tropical rainforest.

Major increase in terrestrial plant carbon occurred during the Paleocene/earliest Eocene in conjunction with a major areal increase in rainforest. During the early Miocene terrestrial global carbon was approximately 1200-1300 gigatons. This figure decreased by about half between the early Miocene and Holocene/Recent. The decrease in terrestrial carbon density resulted from a decrease in area of tropical and subtropical forests and increase in area of deserts, grasslands, and mediterranean woodlands/chapparal. 